\title{
PENGEMBANGAN MODUL TEMATIK BERBASIS STM (SAINS, TEKNOLOGI DAN MASYARAKAT)
}

\author{
Arnelia Dwi Yasa \\ Pendidikan Guru Sekolah Dasar, Universitas Kanjuruhan Malang \\ e-mail: arnelia@unikama.ac.id
}

\begin{abstract}
Module is one form of teaching materials that are packaged in a whole and systematic, so that learners can learn independently. Modules in learning should be tailored to science, technology and society. The purpose of the research is to develop the supplement module in the learning of STM (science, technology and society) thematic module which is valid and interesting. Data were collected through questionnaires and documentation. Based on data analysis, it shows that developed modules are valid and interesting for use in learning.
\end{abstract}

Keyword: Thematic module, STM

\begin{abstract}
Abstrak : Modul merupakan salah satu bentuk bahan ajar yang dikemas secara utuh dan sistematis, sehingga peserta didik dapat belajar mandiri. Modul dalam pembelajaran hendaknya disesuaikan sains, teknologi dan masyarakat. Tujuan penelitian untuk mengembangkan modul suplemen dalam pembelajaran berupa modul tematik berbasis STM (sains, teknologi dan masyarakat) yang valid dan menarik. Data dikumpulkan melalui angket dan dokumentasi. Berdasarkan analisis data, menunjukkan bahwa modul yang dikembangkan valid dan menarik untuk digunakan dalam pembelajaran.
\end{abstract}

Kata kunci: Modul tematik, STM

\section{PENDAHULUAN}

Pembelajaran pada Kurikulum 2013 ditekankan pada pengembangan potensi dan pembangunan karakter pada setiap peserta didik sehingga hasil belajar dapat disinergikan antara pendidikan di sekolah, keluarga dan masyarakat. Proses Pembelajaran Kurikulum 2013 tersebut memberikan kesempatan kepada peserta didik untuk mengembangkan potensi mereka menjadi kemampuan yang semakin lama semakin meningkat dalam sikap (spiritual dan sosial), pengetahuan, dan keterampilan yang diperlukan dirinya untuk hidup bermasyarakat, berbangsa, serta berkontribusi pada kesejahteraan hidup umat manusia (Permendikbud, 2014).

Pembelajaran kurikulum 2013 ditujukan untuk mengembangkan potensi peserta didik agar memiliki kemampuan hidup sebagai pribadi dan warga negara yang beriman, produktif, kreatif, inovatif, dan afektif, serta mampu berkontribusi pada kehidupan masyarakat, berbangsa, bernegara, dan berperadaban dunia. Pada kurikulum 2013, konsep materi pada setiap bidang studi belum dijelaskan secara rinci. Materi yang termuat dalam buku siswa juga kurang luas dan mendalam, membuat siswa kurang menguasai konsep karena konsep materi tiap pertemuan pembelajaran berbeda. Oleh karena itu, diperlukan modul untuk meningkatkan pemahaman siswa terhadap materi yang diberikan guru.

Modul merupakan bahan ajar yang dirancang agar siswa dapat belajar secara mandiri. Modul yang baik adalah modul yang memenuhi 3 komponen kelayakan menurut Badan Standar Nasional Pendidikan (BSNP), yaitu komponen kelayakan isi, kelayakan bahasa, dan kelayakan penyajian (Millah, et al., 2012). Modul pembelajaran disusun berdasarkan 
prinsip-prinsip pengembangan modul, meliputi analisis kebutuhan, pengembangan desain modul, implementasi, penilaian, evaluasi dan validasi, serta jaminan kualitas. Dengan modul, peserta didik dapat belajar lebih terarah dan sistematis. Peserta didik dapat menguasai kompetensi yang dituntut oleh kegiatan pembelajaran yang diikutinya.

Modul tematik berbasis STM perlu dikembangkan untuk Tema Lingkungan Sahabat Kita Subtema Usaha Pelestarian Lingkungan. Modul tematik berbasis STM mengangkat permasalahan yang terjadi di lingkungan sekitar siswa sehingga pembelajaran menjadi kontekstual. Pendekatan STM melibatkan siswa dalam penentuan tujuan pembelajaran, prosedur pelaksanaan pembelajaran, pencarian informasi bahan pembelajaran dan evaluasi belajar. Tujuan STM yaitu agar peserta didik memiliki ilmu dan pengetahuan untuk mengambil keputusan terkait masalah yang terjadi di masyarakat.

Pada Subtema Usaha Pelestarian Lingkungan terdapat permasalahan tentang air kotor dari aspek sains, permasalahan air kotor berdampak pada kesehatan masyarakat. Oleh karena itu diperlukan pengolahan air kotor dengan menggunakan teknologi sederhana untuk mencegah pencemaran lingkungan masyarakat. Dari permasalahan-permasalahan yang ada pada modul tematik berbasis STM siswa akan belajar memecahkan masalah yang terjadi di lingkungan masyarakat sehingga keterampilan siswa dalam memecahkan permasalahan dapat meningkat. Menurut Sugiyanto (2012) dalam pembelajaran berbasis Saling temas ini siswa dibawa pada suasana yang dekat dengan kehidupan nyata siswa sehingga diharapkan siswa dapat mengembangkan pengetahuan yang telah dimiliki untuk dapat menyelesaikan masalah-masalah yang diprediksikan akan muncul di sekitar kehidupannya.

Modul tematik berbasis STM digunakan untuk mengembangkan keterampilan siswa dalam memecahkan permasalahan yang ada dikehidupa sehari-hari. Penelitian ini menggunakan rancangan penelitian pengembangan dengan model Borg \& Gall.

\section{METODE}

Penelitian dilaksanakan di SDN Sawahan Mojokerto pada semester ganjil. Responden yang dipilih adalah pakar, guru dan siswa. Uji coba skala kecil dilakukan pada lima siswa kelas V. Penelitian ini termasuk dalam penelitian pengembangan karena menghasilkan produk berupa modul tematik berbasis STM. Model pengembangan yang digunakan yaitu Borg \& Gall (1983). Tujuan penelitian ini untuk mengembangan modul yang valid dan menarik.

Tahap pengembangan Borg \& Gall terdiri atas (1) penelitian/studi pendahuluan dan pengumpulan data (research and information collecting), (2) perencanaan (planning), pengembangan draf produk (develop preliminary form of product), (4) uji coba lapangan awal (preliminary field testing) atau dalam penelitian ini merupakan uji validasi oleh ahli, (5) merevisi hasil uji coba lapangan awal (main product revision), (6) uji coba lapangan utama atau dalam penelitian ini adalah uji coba skala kecil (main field testing), (7) merevisi produk hasil uji lapangan utama (operational product revision), (8) uji pelaksanaan lapangan atau dalam penelitian ini adalah uji coba lapangan/kelas (operational field testing), (9) revisi produk akhir (final product revision), dan (10) diseminasi dan implementasi (dissemination and 
implementation). Dari sepuluh tahap pengembangan yang dikemukakan oleh Borg \& Gall, hanya tujuh tahap yang dilaksanakan. Penelitian dan pengembangan ini tidak sampai pada tahap uji pelaksanaan lapangan dan diseminasi produk karena terbatasnya waktu dan dana penelitian.

Instrumen pengumpulan data yang digunakan dalam penelitian dan pengembangan modul ini adalah pedoman wawancara, lembar observasi, lembar pengamatan proses, angket. Teknik analisis yang digunakan adalah analisis data kualitatif dan analisis data kuantitatif. Analisis data kualitatif diperoleh dari masukan, saran dari validator ahli isi/ materi, ahli bahasa, desain pembelajaran. Analisis data kuantitatif diperoleh dari skor angket. Data yang diperoleh dari angket validasi para ahli dianalisis dengan persentase yang menggunakan rumus. Rumus untuk mengolah data hasil validasi kepada para ahli diadaptasi dengan modifikasi dari Akbar (2012) adalah sebagai berikut:

$$
\begin{gathered}
V m=\frac{T S e}{T S h} \times 100 \% V d=\frac{T S e}{T S h} \times \begin{array}{c}
1 \mathrm{nn0} / \\
V b=\frac{T S e}{T S h} \times 100 \%
\end{array} \\
V t=\frac{V m+V d}{2}=\cdots \%
\end{gathered}
$$

Keterangan:

$\mathrm{Vm}=$ Validitas ahli materi/isi

$\mathrm{Vd} \quad=$ Validitas ahli desain

$\mathrm{Vb}=$ Validasi bahasa

Tse $\quad=$ Total Skor Empirik yang dicapai (berdasarkan penilaian ahli)

TSh = Total skor yang diharapkan

$\mathrm{Vt}=$ Validasi total/gabung

$100 \%=$ konstanta

Tabel 1. Kriteria Kevalidan Modul Komik Tematik

Berbasis STM

\begin{tabular}{lll}
\hline No & \multicolumn{1}{c}{ Skor } & \multicolumn{1}{c}{ Tingkat Kevalidan } \\
\hline 1 & $86 \%-$ & $\begin{array}{l}\text { Sangat Valid (dapat digunakan } \\
\text { tanpa revisi) }\end{array}$ \\
\hline 2 & $700 \%$ & $\begin{array}{l}\text { cukup Valid (dapat digunakan } \\
\text { dengan revisi) }\end{array}$ \\
\hline 3 & $60 \%-69 \%$ & $\begin{array}{l}\text { tidak Valid (tidak } \\
\text { dapat digunakan) }\end{array}$ \\
& &
\end{tabular}

\begin{tabular}{l}
\hline $4 \quad 0 \%-59 \%$ \\
Sumber:
\end{tabular}

dengan modifikasi, 2011:147)

Data kemenarikan diperoleh dari angket yang diberikan kepada lima siswa dalam menggunakan modul. Untuk mengolah data kemenarikan dari angket yang diberikan kepada siswa, digunakan rumus yang dimodifikasi dari Hobri (2010).

$$
M=\frac{\sum A}{n}
$$

Keterangan:

$\mathrm{M}=$ Kemenarikan dari siswa

$\sum A=$ Jumlah nilai untuk semua indikator

$\mathrm{n} \quad=$ Skor maksimal

Adapun kriteria kemenarikan yang digunakan sebagai pedoman interpretasi terdapat pada tabel 2 berikut.

Tabel 2 Kriteria Kemenarikan Modul Tematik Berbasis STM

\begin{tabular}{lcl}
\hline No & Skor & \multicolumn{1}{c}{ Tingkat Kevalidan } \\
\hline 1 & $86 \%-100 \%$ & $\begin{array}{l}\text { Sangat menarik, tidak perlu } \\
\text { revisi }\end{array}$ \\
\hline 2 & $70 \%-85 \%$ & $\begin{array}{l}\text { Cukup menarik, tidak perlu } \\
\text { revisi }\end{array}$ \\
\hline 3 & $60 \%-69 \%$ & $\begin{array}{l}\text { Kurang menarik, perlu revisi } \\
\text { keci }\end{array}$ \\
\hline 4 & $0 \%-59 \%$ & Tidak menarik, revisi total \\
$\begin{array}{l}\text { (Sumber: diadaptasi dari Akbar\&Sriwiyana } \\
\text { dengan }\end{array}$ \\
modifikasi, 2011)
\end{tabular}

\section{HASIL DAN PEMBAHASAN}

Hasil studi pendahuluan menunjukkan bahwa terdapat beberapa permasalahan dalam pembelajaran, yakni (1) modul yang digunakan di 
sekolah belum sesuai dengan lingkungan sekitar siswa, (2) isi dari modul belum disesuaikan dengan (sains, teknologi dan masyarakat) yang ada disekitar siswa, (3) desain dari modul hanya sedikit memuat gambar yang ada dilingkungan sekitar siswa, (4) siswa belum mengetahui keunikan yang ada di lingkungan tempat tinggal siswa.

Berdasarkan hasil studi pendahuluan, terdapat permasalahan dari modul yang digunakan oleh siswa. Oleh karena itu, peneliti membuat perencanaan untuk mengembangkan modul yang berfungsi sebagai suplemen buku ajar yang sudah ada. Modul yang dikembangkan berupa modul siswa berbasis STM.

Modul yang dikembangkan dalam penelitian ini adalah modul tematik berbasis STM untuk siswa kelas V Sekolah Dasar. Modul memuat (1) kata pengantar, (2) petunjuk penggunaan modul, (3) bagian-bagian modul dan (4) daftar isi. Bagian isi memuat (1) tujuan pembelajaran, (2) uraian materi, (3) latihan, (4) kesimpulan, (5) tes akhir modul. Sementara itu, pada bagian penutup memuat: (1) daftar rujukan, (2) pedoman penilaian.

Penelitian pengembangan dimulai dari pembuatan draf awal produk. Modul disusun dengan menggunakan font Comic Sans MS. Pemilihan huruf ini disesuaikan dengan karakter dari siswa kelas V. Draf awal produk divalidasikan kepada 3 orang ahli yakni ahli materi, media dan bahasa. Hasil validasi dari ahli materi menunjukkan bahwa rata-rata kevalidan modul $90 \%$ yang berarti modul sangat valid dapat digunakan tanpa revisi dari segi materi. Meskipun demikian, penulis tetap melakukan revisi sesuai saran yang diberikan oleh validator. Saran perbaikan dari hasil validasi ahli materi serta revisi dapat dilihat pada Tabel 3.

Tabel 3. Saran dari Ahli Materi dan Revisi yang Dilakukan

\begin{tabular}{|c|c|c|}
\hline Bagian & $\begin{array}{l}\text { Sebelum } \\
\text { Revisi }\end{array}$ & Sesudah revisi \\
\hline Modul & $\begin{array}{l}\text { 1. Belum ada } \\
\text { peta konsep } \\
\text { 2. Belum ada } \\
\text { kegiatan } \\
\text { diskusi } \\
\text { 3. Penambahan } \\
\text { materi yang } \\
\text { berbasis } \\
\text { STM }\end{array}$ & $\begin{array}{l}\text { 1. Sudah } \\
\text { direvisi } \\
\text { 2. Sudah } \\
\text { direvisi } \\
\text { 3. Sudah } \\
\text { direvisi }\end{array}$ \\
\hline
\end{tabular}

Validasi media diperlukan untuk mengevaluasi media pada modul yang dikembangkan. Data yang diperoleh berupa data kuantitatif dan kualitatif melalui angket yang diberikan peneliti kepada ahli media. Peneliti memberikan angket validasi media terhadap produk yang dikembangkan.

Hasil validasi oleh ahli media menunjukkan bahwa rata-rata persentase kevalidan modul sebesar $85 \%$ yang berarti modul siswa cukup valid dan dapat digunakan dengan revisi. Peneliti juga memerhatikan saran dari validator untuk perbaikan produk selanjutnya. Saran perbaikan dari hasil validasi ahli media serta revisi dapat dilihat pada Tabel 4.

Tabel 4. Saran dari Ahli Media dan Revisi yang dilakukan

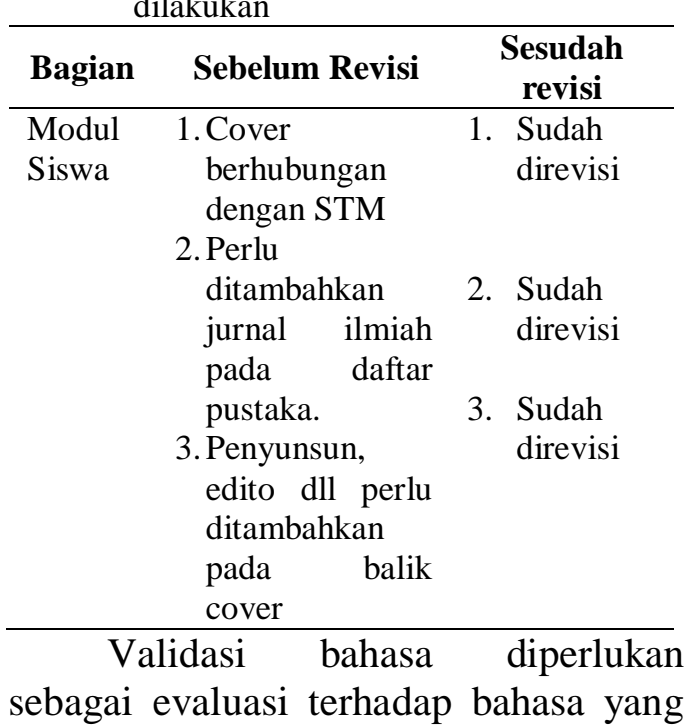


digunakan dalam modul yang sudah dikembangkan oleh peneliti. Penggunaan bahasa yang efektif dan komunikatif penting dalam sebuah modul. Dengan demikian, aspek ini perlu divalidasi. Data yang diperoleh berupa data kuantitatif dan kualitatif melalui angket yang diberikan peneliti kepada ahli bahasa. Peneliti memberikan angket validasi bahasa terhadap produk yang dikembangkan kepada ahli bahasa.

Persentase kevalidan modul siswa oleh ahli bahasa sebesar $93 \%$ yang berarti modul sangat valid. Hasil ini menunjukkan bahwa modul yang dikembangkan tergolong sangat valid dan dapat diterapkan meski tanpa revisi. Revisi tetap dilakukan peneliti berdasarkan saran dari ahli agar buku semakin baik. Saran perbaikan dari hasil validasi ahli bahasa serta revisi dapat dilihat pada Tabel 5.

Tabel 5. Saran dari Ahli Bahasa dan Revisi yang dilakukan

\begin{tabular}{lll}
\hline Bagian & Sebelum Revisi & \multicolumn{1}{c}{$\begin{array}{c}\text { Sesudah } \\
\text { revisi }\end{array}$} \\
\hline Modul & Penulisan EYD & Sudah \\
Siswa & perlu diperhatikan & direvisi \\
\hline
\end{tabular}

Berdasarkan paparan data

kevalidan produk ditinjau dari isi, bahasa, dan media pada modul oleh para ahli, didapatkan rekapitulasi validasi total atau gabungan pada Tabel 6 berikut ini.

Tabel 6 Rekapitulasi Data Validasi Total Modul Komik Tematik Berbasis STM

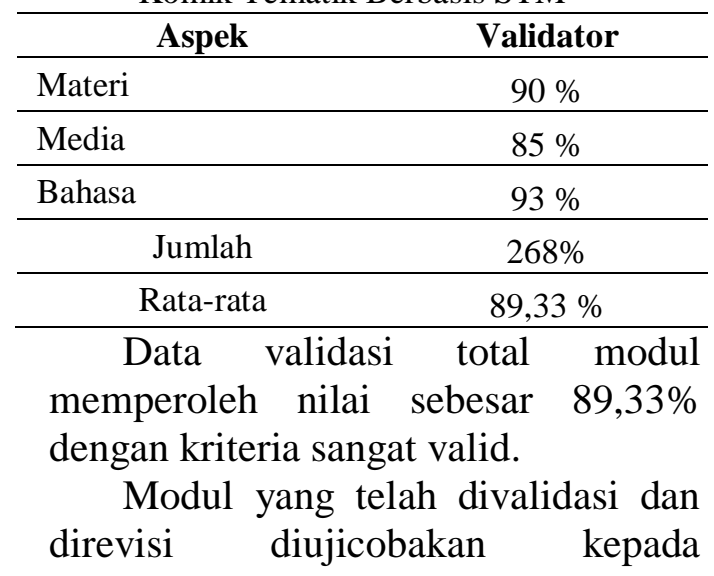

kelompok kecil yang terdiri dari lima siswa untuk mengetahui kemenarikannya. Hasil uji coba kemenarikan modul mendapatkan prosentase sebesar $89 \%$ yang berarti modul sangat menarik. Pada angket yang diberikan kepada siswa tidak ada saran yang negative terhadap modul. Komentar yang muncul antara lain (1) tampilan modul menarik karena banyak gambar dan warnanya menarik; (2) materi yang ada pada modul mudah untuk dipahami karena mengankat permasalahan dan menggambarkan lingkungan sekitar; (3) bahasa yang digunakan dalam modul mudah untuk dipahami. Komentar siswa pada modul yang dikembangkan positif, meskipun demikian perlu mencermati modul kembali untuk perbaikan. Perbaikan yang dilakukan tertera pada tabel 7 .

Tabel 7. Revisi Setelah Uji Coba Kelompok Kecil

\begin{tabular}{|c|c|c|}
\hline Bagian & Sebelum Revisi & $\begin{array}{l}\text { Sesudah } \\
\text { revisi }\end{array}$ \\
\hline $\begin{array}{l}\text { Modul } \\
\text { Siswa }\end{array}$ & $\begin{array}{l}\text { 1. Ada beberapa } \\
\text { gambar yang } \\
\text { kurang jelas } \\
\text { 2. Perlu perbaikan } \\
\text { pada EYD } \\
\text { dibeberapa } \\
\text { kalimat. }\end{array}$ & $\begin{array}{ll}\text { 1. } & \begin{array}{l}\text { Sudah } \\
\text { direvis }\end{array} \\
\text { 2. } & \begin{array}{l}\text { Sudah } \\
\text { direvis }\end{array}\end{array}$ \\
\hline
\end{tabular}
telah dilakukan, dapat disimpulkan bahwa modul tematik berbasis STM yang dikembangkan telah memenuhi kriteria valid dan menarik yang dapat digunakan dalam pembelajaran. Hal ini didukung dengan pendapat Akker (dalam Sofnidar \& Sabil, 2012) yang menyatakan bahwa kualitas perangkat pembelajaran setidaknya dilihat dari kriteria kevalidan (validity) dan kepraktisan (practically).

\section{KESIMPULAN}

Penelitian

menghasilkan suatu produk berupa 
modul tematik berbasis STM untuk siswa kelas V Sekolah Dasar pada Tema Lingkungan Sahabat Kita Subtema Usaha Pelestarian Lingkungan. Berdasarkan hasil penelitian disimpulkan bahwa modul yang dikembangkan dalam penelitian ini, dikategorikan valid dan menarik digunakan dalam pembelajaran.

Valid tergambar dari hasil penilaian validator bahwa semua validator menyatakan hasil yang baik pada ketiga aspek, yaitu materi, media dan bahasa. Menarik tergambar dari penilaian siswa saat uji coba kelompok kecil.

\section{SARAN}

Modul yang dihasikan dalam penelitian ini adalah sebagai modul pelengkap dalam pembelajaran kelas $\mathrm{V}$ Tema Lingkungan Sahabat Kita Subtema Usaha Pelestarian Lingkungan. Disarankan pada peneliti lain untuk mengembangkan modul untuk tema atau subtema yang lain.

\section{DAFTAR PUSTAKA}

Akbar, S. 2015. Instrumen Perangkat Pembelajaran. Bandung: Rosdakarya.

Arum, S. 2016. Pengembangan Modul Pembelajaran Tematik Integratif Subtema Hubungan Makhluk Hidup Dalam Ekosistem Pendekatan Saintifik Untuk Kelas 5 SD. Jurnal Scholaria. 6(3):239250.

Badan Standar Nasional Pendidikan. 2006. Instrumen Penilaian Tahap II Buku Teks Pelajaran Pendidikan Dasar dan Menengah. Jakarta: BSNP. Tersedia di http://www.scribd.com.

Borg \& Gall. 1983. Educational Research: An Introduction. New York and London: Longman Inc.
Dick, Walter., Lou Carrey, James O. Carrey.2009. The Systematic Design of Instruction (7th Edition). New Jersey: Pearson Education, Inc.

Haryani, dkk. 2013. Pengengambangan Modul IPA Terpadu bervisi SETS (Science, Enviroment, Technology, and Society) Pada Tema Ekosistem. Unnes Science Educational Journal.2(1):180-187.

Kemendikbud. 2014. Panduan Teknis Pembelajaran dan Penilaian. Jakarta: Kementrian Pendidikan dan Kebudayaan.

Sugiyanto, dkk. 2012. Pengembangan modul IPA Terpadu berbasis sains, lingkungan, teknologi masyarakat dengan tema teknologi biogas. Jurnal Kependidikan.42(1):54-60.

Su'udiah, dkk. 2016. Pengembangan Buku Teks Tematik Berbasis Kontekstual. Jurnal Pendidikan. 1(9):1744-1748.

Sofnidar, \& Sabil, H. 2012. Pengembangan Bahan Ajar Pendidikan Matematika I dengan Pendekatan Kontekstual, Jurnal Pendidikan Matematika. 2 (2).

Mikdar, S. 2006. Penelitian Model pembelajaran Sains Teknologi Masyarakat (STM) Dalam Pendidikan Demokrasi Dengan Menggunakan Modul. Jurdik dan Hum. 9:8-22.

Millah, E. S., L.S. Budipramana, \& Isnawati. 2012. Pengembangan Buku Ajar Materi Bioteknologi Di Kelas XII SMA IPIEMS Surabaya Berorientasi Sains, Teknologi, Lingkungan dan Masyarakat (SETS). Electronic journal Bioedu. 1(1): 19-24. 